\title{
Primitive Neuroectodermal Tumor of Maxilla - A Rare Case Report in Adult
}

\author{
Mahesh KP ${ }^{1 *}$ and Karthikeya Patil ${ }^{2}$ \\ ${ }^{1}$ Reader, JSS Dental College and Hospital, JSSAHER, Mysore, Karnataka, India \\ ${ }^{2}$ Professor and Head, JSS Dental College and Hospital, JSSAHER, Mysore, \\ Karnataka, India
}

*Corresponding Author: Mahesh KP, Reader, JSS Dental College and Hospital, JSSAHER, Mysore, Karnataka, India.
Received: May 14, 2020

Published: June 04, 2020

(C) All rights are reserved by Mahesh KP and

Karthikeya Patil.

\begin{abstract}
Primitive neuroectodermal tumor (PNET) includes a wide array of lesions with varying central and peripheral nervous system having differentiating potential. It is their insidious clinical symptoms, varying locations and rarity, the accurate diagnosis of peripheral PNETs poses a challenge for clinicians. PNETs has diagnostically characteristic immunophenotypical and genetic features that distinguish them from other small round cell tumors. We recently got to treat a patient with maxillary swelling on the left side of the face, its clinical course, histopathology with immunohistochemistry correlation of this rare entity PNET is discussed.

Keywords: PNET; NSE; CD45
\end{abstract}

\section{Introduction}

Primitive neuroectodermal tumor (PNET) is a term used to describe category of neoplasm's of neuroectodermal origin with variable cell differentiation [1]. Neoplasm comprising of undifferentiated round cells resembles germinal or matrix cells of the embryonic neural tube. PNET is also called as neuroblastoma, cerebral medulloblastoma, undifferentiated small-cell neoplasm, neuroepithelioma, peripheral medulloepithelioma [2]. The diagnosis of PNET is confounded by its clinical and histopathological similarity to Ewing's sarcoma of the bone [3]. t once diagnosed as Ewing's sarcoma are now often designated as peripheral neuroepithelioma or synonymously PNET [4]. It usually found involving bone or soft tissue, chest, limbs and only $3 \%$ of cases reported within the skull and jaws. These tumors are found to be aggressive, high tendency for recurrence, and metastasize especially to bone marrow, brain, lungs and local lymph nodes are reported [3,4]. Few cases are reported to occur in oral cavity and common in children. In the wake of the rarity of PNET in the oral cavity and in adult, one such case occurring in a 60-year-old man involving the posterior part of the palate is reported.

\section{Case Report}

A 60year old man reported to department of oral medicine with Complain of swelling in the upper left back teeth region since 2 months. He has undergone total extraction 1 year back for peri- odontal problems. He is not a denture wearer. Heaviness in the head was noted. Pt also feels left nasal blockage and reddish sticky discharge from left nasal region associated with sleep disturbance since 3 to 4 months. No H/O recent cough, cold, trauma.

Patient gives history of noticing the swelling in upper left back tooth region, two months back which was peanut sized initially which progressed gradually to attain present size in 26 region. Associated with pain, which was insidious in onset, localized, continuous, pulling type, radiating to temporal region. Patient visited a local doctor in his native place where antibiotics and pain killers were given (unknown). No relief was found, then he went to other doctor where same medicine was prescribed, without any further investigation. Patient than reported to JSSDCH, Mysore.

On general and physical examination the patient appeared well nourished and good state of health.

\section{Local examination}

Extra orally well-defined swelling measuring approximately 3 x $2.5 \mathrm{~cm}$ in size evident on left middle $1 / 3^{\text {rd }}$ of the face, extending superiorly below the left infra orbital margin, inferiorly at the level of angle of the mouth, medially from nasolabial-fold extending 2.5 cms laterally. Surface over the swelling and surrounding structure appear normal with no evidence of secondary changes. Palpation reveals the swelling is non tender, soft in consistency and local rise in temperature. 
Intra orally completely edentulous maxillary and mandibular arch. A Solitary swelling in 26, 27, 28 region which was dome shaped involving the left palate, measuring $1.5 \times 2 \mathrm{cms}$ in size. Illdefined borders, surface of the swelling is same as the surrounding normal mucosa. On palpation soft in consistency, non-tender, compressible but not depressible/non reducible. No ulcerations seen over the swelling.

Provisional/differential diagnosis

- Provisional diagnosis

- Antral Malignancy

- Differential diagnosis

- $\quad$ Salivary gland malignancy

- Lymphoma

- Residual infection

- $\quad$ Sino nasal polyp

- Investigations

- Conventional - IOPAR 26, 27, 28 region

- Maxillary Occlusal cross sectional

- PNS

- $\quad$ Computer tomography

- Biopsy

- Immunohistochemistry.

C T report: Suggestive of fairly large, mild enhancing, soft tissue density mass lesion involving the left maxillary antrum and destruction of adjacent boney walls. Mass extending medially into the left nasal cavity and ethmoid sinus, floor of orbit, infratemporal fossa, pterygopalatine fossa. No intracranial extension of the mass and intracranial vascular structure are normally visualized.

Reports suggestive of carcinoma of maxillary antrum?

Patient was referred to Bharath Cancer Institute for further investigation. The routine blood and urine examination done were found to be within normal limits. Biopsy was done in the palatal region under local anesthesia which yielded gelatin-like mass. Histopathological report suggestive of round to oval cells with vesicular nucleus and prominent nucleoli. Tumor cells are arranged in sheets, clusters, and in organoid pattern at places, rosettes appearance is seen. Histopathological report was suggestive of features of malignancy- Round cell tumor.

Histopathological differential diagnosis: Lymphoma, olfactory neuroblastoma (PNET, carcinoma of maxillary sinus.
Suggestion for IHC studies given- CD45 and NSE

- $\quad$ IHC for CD45: Negative (non-reactive)

- IHC for NSE (Neuron Sheath Enolase): Highly positive (Reactive)

- NSE: Positivity is found in majority of neuroectodermal and neuroendocrine neoplasms.

- As NSE was positive and CD45 was negative confirms the diagnosis of PNET.

Oncologist decided to treat the patient with chemotherapy and skull base surgery resection after chemotherapy. Patient Showed good recovery after anterior chemotherapy around 25\% in first cycle, further it was found nearly $80 \%$ shrinkage was seen.

\section{Discussion}

PNET is a term to describe a category of neoplasms of neuroectodermal origin with variable cell differentiation. Recent concept of PNET is expanded to include peripherally located tumors, referred to as $\mathrm{p}$ PNETs or peripheral PNETs (Oral Disease 2005). PNET is a rare tumor, commonly affecting mainly children and young adults, rarely seen in adults. Rarely seen in oral cavity but not spared, only few cases are reported. It usually involves bone or soft tissue and only $3 \%$ have been reported within the skull and jaws. These tumors are aggressive, tendency to recur and to metastasis to bone marrow, brain, lungs and lymph nodes. PNET describes neoplasm composed of undifferentiated round cells resembling germinal or matrix cells of neural tube. PNET represents transition between neoplastic Schwann cells, neuroblasts, and paraganglionic elements. Migratory neuroectodermal cells in extra central nervous system give rise to neuroectodermal tumors.

Many PNETs and related neoplasms like neuroblastoma are biologically active, capable of elaborating a variety of catecholamine precursors, and their metabolites like vanillylmandelic acid, homovanillic acid or both are secreted in $80 \%$ of patients. Urinary vanillylmandelic acid and homovanillic acid are used as biological markers to aid in diagnosis and monitor the prognosis of treatment. It is not a definitive markers as PNETs are non-secretory and the value of metabolites will be within normal limits. Other diagnostic modalities include monoclonal antibodies and immunochemical markers such as neuron - specific enolase and leucocyte common antigen $[4,5]$. In these case neuron specific enolase is used a diagnostic markers. 
PNET in maxilla, possibility of olfactory neuroblastoma must be considered. Intracytoplasmic neurosecretory granules is a prerequisite for the diagnosis of olfactory neuroblastoma, which was not seen in our histopathological analysis. Olfactory neuroblastoma is a peripheral PNET related to Ewing's sarcoma. Antibody markers like NSE, S-100, Leu-7, chromogranin and neurofilaments which specifically label PNET which are negative for Ewing's sarcoma $[6,7]$.

\section{Conclusion}

A rare documentation of oral PNET in adult is reported. PNET to be considered as one of the differential diagnosis in any maxillary swelling. Immunohistochemical markers proved to be useful in establishing the diagnosis so proper diagnostic and investigatory protocols to be followed for early detection and treatment.

\section{Bibliography}

1. Arvind Krishnamurthy., et al. "Primary peripheral primitive neuroectodermal tumor of the mandible". Annals of Maxillofacial Surgery 3.2 (2013): 192-194.

2. Mills SE. "Neuroectodermal neoplasms of the head and neck with emphasis on neuroendocrine carcinoma". Modern Pathology 15.3 (2002): 264-278.

3. Kulkarni MM., et al. "A rare case of extra skeletal Ewing's sarcoma/primitive neuroectodermal tumor developing in maxillary sinus of an old patient". Journal of Oral and Maxillofacial Pathology 20.2 (2016): 330.

4. Enver Özera., et al. "Primitive neuroectodermal tumour of the mandible". International Journal of Pediatric Otorhinolaryngology 65.3 (2002): 257-260.

5. Masayuki Shintaku., et al. "Malignant peripheral nerve sheath tumor of small round cell type with pleomorphic spindle cell sarcomatous areas". Pathology International 53.7 (2003): 478482.

6. Arti Rameshrao Anvikar., et al. "Malignant Peripheral Nerve Sheath Tumor with Primitive Neuroepithelial Differentiation in an Adult". International Journal of Surgical Pathology 20.5 (2011): 511-514.

7. Votta TJ., et al. "Peripheral primitive neuroectodermal tumor associated with the anterior mandible: a case report and review of the literature". Oral Surgery, Oral Medicine, Oral Pathology, Oral Radiology, and Endodontology 100.5 (2005): 592-597.

\section{Assets from publication with us}

- Prompt Acknowledgement after receiving the article

- Thorough Double blinded peer review

- Rapid Publication

- Issue of Publication Certificate

- High visibility of your Published work

Website: www.actascientific.com/

Submit Article: www.actascientific.com/submission.php Email us: editor@actascientific.com

Contact us: +919182824667 